\title{
Numerical Investigation on Flexural Buckling Behavior of Hot-rolled Steel Columns at Elevated Temperatures
}

\author{
Samer Nemer ${ }^{1 *}$, Ferenc Papp ${ }^{1}$ \\ ${ }^{1}$ Department of Structural and Geotechnical Engineering, Faculty of Architecture, Civil Engineering and Transport sciences. Széchenyi \\ István University, Egyetem tér 1, 9026 Győr, Hungary \\ *Corresponding author, e-mail: samer.nemer@hallgato.sze.hu
}

Received: 04 January 2021, Accepted: 08 April 2021, Published online: 20 April 2021

\begin{abstract}
In this paper, a numerical investigation on the global buckling capacity of the axially compressed steel columns with hot-rolled I crosssection at elevated temperatures is presented. Geometrically and materially non-linear finite element model and the ABAQUS software were used to determine the buckling resistance. The numerical ABAQUS model was validated using experimental results available in the literature, and then the validated numerical model was used to generate a database of load-carrying capacity. The parametric study covered three different cross-section classes (class 1, 2 and 3), ten different non-dimensional slenderness $\bar{\lambda}=0.5,0.6,0.7,0.9$, $1.1,1.3,1.5,1.7,1.9,2.0)$, three different temperatures $\left(400^{\circ} \mathrm{C}, 500^{\circ} \mathrm{C}, 600^{\circ} \mathrm{C}\right)$, and two stress-strain constitutive relations including (the nonlinear material model adopted in the European guidance for structural fire design EN1993-1-2, and a Bilinear material model), with and without residual stress. The influence of the model parameters on the load capacity of steel columns at elevated temperatures was evaluated. The results of the parametric study were compared with the results of the simplified calculation model presented in EN1993-1-2.
\end{abstract}

Keywords

buckling, steel, columns, elevated temperatures, fire design

\section{Introduction}

The steel structural design involves determining the bucking resistance of structural members. Columns are considered the most crucial parts of any structure because they support loads from all other members. Buckling behavior of steel columns at elevated temperatures is a complex phenomenon as it is affected by many factors (e.g., geometry of the cross-section, fabrication method, steel temperature, slenderness ration, material properties, width to thickness ratios, residual stress, etc.).

In design practice, EN 1993-1-2 [1] gives a simplified calculation method for designing steel columns at elevated temperatures. This design method was proposed by Franssen et al. in [2] and [3], and was based on AyrtonPerry formulation [4]. However, the response of steel columns at elevated temperatures becomes highly nonlinear which makes this simplified method not suitable in certain ranges of parameters [5].

Numbers of experimental and numerical investigations have been carried out to understand the overall buckling behaviors of steel columns at elevated temperatures.
Yang et al. [6] investigated experimentally the influence of width to thickness ratios, slenderness ratios and residual stress on the performance of fire-resistant steel $\mathrm{H}$-columns. The results showed that column strength is sensitive to slenderness at temperatures less than $600 \square$, while the strength of a slender column decreases sharply for temperatures above $600 \square$. Moreover, the failure mode of fire-resistant steel H-columns changed from inelastic global buckling at ambient temperature to local buckling at elevated temperatures. Wang et al. [7] carried out compression tests on 8 welded $\mathrm{H}$-shaped steel stub columns at two temperatures of $450^{\circ} \mathrm{C}$ and $650^{\circ} \mathrm{C}$, showing that EN 1993 Part 1.2 and 1.5 provisions for local buckling predict higher capacities than those obtained from fire tests by up to $30 \%$. One of the most notable works in this field has been achieved in Swiss Federal Institute of Technology Zurich by Pauli et al. [8]. An extensive experimental research was carried out in order to investigate the behavior of steel columns under fire conditions. The test results showed that the simplified design approach presented in 
EN 1993-1-2 does not accurately predict the ultimate load of steel columns at elevated temperatures, because the cross-sectional capacity is not determined correctly [9]. Even in cases where the correct cross-sectional resistance obtained, the buckling curves ignore the non-linearity of the steel behavior at elevated temperatures and fail to correctly determine the buckling capacities of columns. Gomes et al. [10] reported that the resistance of steel columns at elevated temperatures is very sensitive to the column slenderness.

It was concluded that the provisions of the EN 1993-1-2 part 4.2.3.2 (Fig. 4.1) for the buckling length of steel columns may be unsafe in many situations, particularly in the case of fire in an intermediate story. The stability of axially loaded steel columns with square hollow sections at elevated temperatures was investigated by Kervalishvili and Talvik [11], showing that the simplified method presented in part 4.2.3.2 of EN 1993-1-2 is adequate for temperature range from $200^{\circ} \mathrm{C}$ to $300^{\circ} \mathrm{C}$. On the other hand, for other temperatures, and for slenderness values less than 1.0, it was proved that the simplified method of EN 1993-1-2 overestimates the buckling capacity of the studied columns by up to $45 \%$. While for slenderness values greater than 1.0 , the simplified method underestimates the load-bearing capacity compared to numerical analysis by up to $25 \%$. The stability behavior of steel columns with square and rectangular hollow sections subjected to fire has been analytically and experimentally investigated by Knobloch et al. [12]. It was reported that the influence of the nonlinear stressstrain relationship of steel at elevated temperatures on overall buckling strength need to be considered. Moreover, adopting the temperature-dependent stress reached at $2 \%$ strain leads to unconservative results for the cross-sectional capacity in pure compression. Chen et al. [13] conducted both experimental and numerical investigations on mechanical behavior of I-section steel columns. The results showed that when the slenderness ratio of the column $(\lambda)$ was less than 50, the column failed due to local buckling, but when the slenderness ratio of the column was more than 50, the column failed due to global buckling. On the other hand, the elevated temperatures had no evident influences on failure modes of the columns.

\subsection{Problem statement}

Based on the allowable literature described above, the influence of several factors on buckling capacity of steel columns at elevated temperatures is diverse and should be accurately considered to avoid oversimplification.
Moreover, the information on the effects of these factors on hot-rolled I-section steel columns at elevated temperatures is not sufficient and contradictory for some cases. Thus, the analysis of these members in these conditions is still desirable: generalized review about the effect of different factors on buckling strength of steel columns at elevated temperatures should be provided.

Therefore, the purpose of this research is to investigate the effect of three parameters, namely: slenderness ratio, residual stress, and material model, on the response of steel columns made of different hot-rolled (IPE, HEA) cross-sections at elevated temperatures.

\subsection{The provisions of EN1993-1-2 code}

At present the equations used in fire situations are different from the ones used at room temperature. According to EN 1993-1-2 provisions [1], the design buckling resistance $N_{b, f i, t, R d}$ of a compressed member with a Class 1, Class 2, or Class 3 cross-section with a uniform temperature $\theta_{a}$ at time $t$ should be determined as follows:

$N_{b, f i, t, R d}=\chi_{f i} A k_{y, \theta} f_{y} / \gamma_{M, f i}$

where $\chi_{f i}$ is the reduction factor for flexural buckling in the fire design situation.

$k_{y, \theta}$ is the reduction factor for the yield strength of steel at the steel temperature $\theta_{a}$ reached at time $t$.

$\gamma_{M, f i}$ is the safety factor for the fire design situation.

$A$ is the area of the cross-section.

The cross-sectional compression capacity reduction coefficient should be determined according to the following equation:

$$
\chi_{f i}=\frac{1}{\varphi_{\theta}+\sqrt{\varphi_{\theta}^{2}-\bar{\lambda}_{\theta}^{2}}},
$$

where $\varphi_{\theta}=\frac{1}{2}\left[1+\alpha \bar{\lambda}_{\theta}+\bar{\lambda}_{\theta}^{2}\right]$, the imperfection factor is given as $\alpha=\beta \sqrt{235 / f_{y}}$, where $\beta=0.65$.

The non-dimensional slenderness $\bar{\lambda}_{\theta}$ at the temperature $\theta_{a}$ is given as:

$\bar{\lambda}_{\theta}=\bar{\lambda}\left[k_{y, \theta} / k_{E, \theta}\right]^{0.5}$,

where $k_{E, \theta}$ is the reduction factor for the slope of the linear elastic range at the steel temperature $\theta_{a}$ reached at time $t$, and $\bar{\lambda}$ is the nondimensional slenderness at ambient temperature, which can be calculated according to EN1993-1-1 as: $\bar{\lambda}=\sqrt{\frac{A f_{y}}{N_{c r}}}$, and $N_{c r}$ is the lowest elastic critical load at ambient temperature. 


\section{Numerical model}

\subsection{Case study}

Simply supported concentrically compressed steel members are considered for this study, as shown in Fig. 1.

The program of the numerical study is consisted of four cross-sections. Ten different non-dimensional slenderness $(\bar{\lambda}=0.5,0.6,0.7,0.9,1.1,1.3,1.5,1.7,1.9,2.0)$ were selected to model the columns at 3 different temperatures (400 $\square$, $500 \square, 600 \square$ ). A total of 500 numerical simulations were conducted. Steel grade S235 was used for all members.

The geometry of the cross-sections those are used in this study, along with the classes of these cross-sections under compression are shown in Table 1.

\subsection{Model description}

The load carrying capacity of the steel columns were calculated using the commercial software ABAQUS. The members were modeled using the general purpose S4R shell elements. In the finite element model, the cross section (modeled using shell elements) is not totally similar to the actual cross section of steel hot-rolled I-shaped columns, because of the following reasons: First, the fillet radius at the web-flange intersections cannot be modeled. Secondly, there is a small area at the modeled cross-section at the web-flange intersection that is taken into account twice. These geometrical errors were compensated for by adding B32 beam elements at the web-flange intersections, as shown in Fig. 2.

A calculated profile is assigned to beam elements to compensate for the lacking properties.

The mesh size was determined to be 16 elements in the flange, 16 elements in the web depth and with size of 20 $\mathrm{mm}$ across the beam length as shown in Fig. 3.

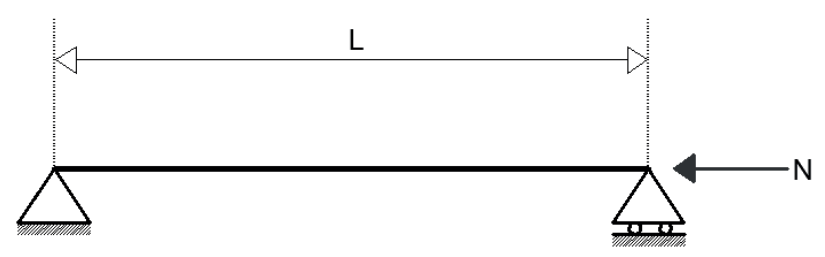

Fig. 1 The studied member

Table 1 Properties of the cross-sections

\begin{tabular}{lcccccc}
\hline $\begin{array}{l}\text { Cross- } \\
\text { section }\end{array}$ & $\begin{array}{c}h \\
(\mathrm{~mm})\end{array}$ & $\begin{array}{c}b \\
(\mathrm{~mm})\end{array}$ & $\begin{array}{c}t_{w} \\
(\mathrm{~mm})\end{array}$ & $\begin{array}{c}t_{f} \\
(\mathrm{~mm})\end{array}$ & $\begin{array}{c}A \\
\left(\mathrm{~mm}_{2}\right)\end{array}$ & $\begin{array}{c}\text { class of } \\
\text { cross- section }\end{array}$ \\
\hline IPE 180 & 180 & 91 & 5.3 & 8 & 2395 & 1 \\
IPE 300 & 300 & 150 & 7.1 & 10.7 & 5381 & 3 \\
HE240A & 230 & 240 & 7.5 & 12 & 7684 & 2 \\
HE300A & 290 & 300 & 8.5 & 14 & 11253 & 2 \\
\hline
\end{tabular}

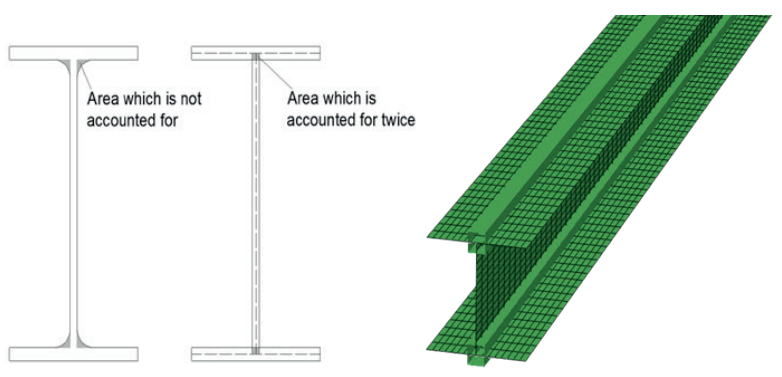

Fig. 2 (left) Real section vs. FE model section; (right) modelled cross-section

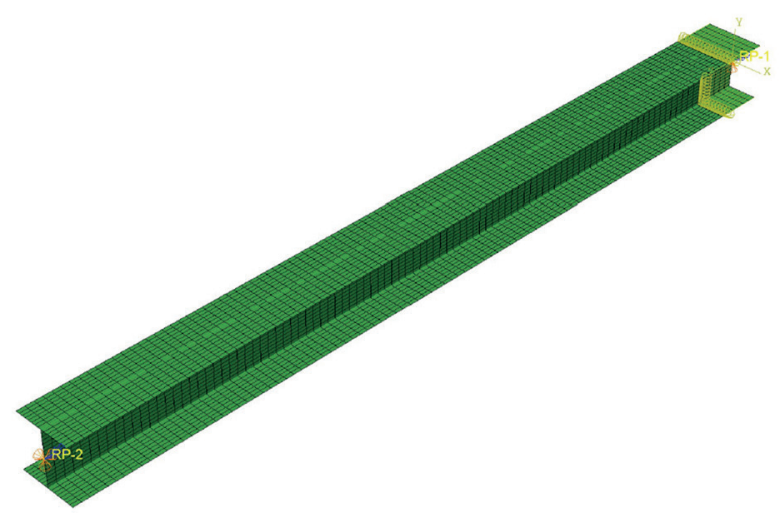

Fig. 3 Geometry and meshing of the FE model and the applied load

\subsection{Boundary conditions and load application}

The columns are pin-supported. In order to simulate these boundary conditions, two reference points (one at each side) were coupled with the nodes of both end surfaces of the column using kinematic coupling restraints.

Boundary conditions were applied through these reference points at the column ends as follows:

The reference points of the column were restrained against all degrees of freedom except for the displacement in the direction of the applied load at the loaded end, and the rotations about the axes of buckling at both ends.

The load was modeled by applying distributed forces (by means of nodal forces) on the flanges and on the web of the loaded end, as shown in Fig. 3, using the modified RIKS tool (also known as Arc length method) available in the ABAQUS library.

\subsection{Geometrical imperfection and residual stress}

In the numerical analysis, the initial geometrical imperfections of columns were determined by first performing a linear buckling analysis (LBA) on the perfect prismatic column with given boundary conditions, then the relevant normalized global buckling mode (in the relevant plane of buckling) is extracted. Thus, the first (lowest) global buckling mode shape derived by the linear buckling 
analysis was introduced into non-linear finite element model (GMNIA), multiplying this by the amplitude of initial geometrical (bow) imperfection and updating the nodal coordinates of the model by adding the established nodal imperfections.

The amplitude of initial geometrical imperfection of the column was taken equals to L/1000, which is used in most studies in the literature and corresponds to $75 \%$ of the recommended tolerance value of $\mathrm{L}=750$ for steel column in Annex D of EN 1090-2:2008 [14] (where L is the column length).

The residual stress distribution considered in this study is according to ECCS [15] for hot-rolled cross-sections which is the basis for the European buckling curves and the most commonly used residual stress pattern for hotrolled I profiles in numerical simulations. The magnitude of the initial stress depends on height to width ratio of the section analyzed, as illustrated in Fig. 4.

In reality, it would be wrong to apply residual stress patterns presented in Fig. 4 into the model with mechanical properties corresponding to the elevated temperature conditions. Therefore, residual stress was introduced as initial stresses at normal temperature, and a static analysis step with temperature varies from normal to the temperature under consideration was performed as described by Franssen [16].

\subsection{Numerical model validation}

The axial load capacities obtained from the ABAQUS model described above are compared with the ultimate loads measured in the test performed by Pauli et al. [8], as presented in Table 2. It can be seen that the predicted buckling loads are generally in good agreement with the test results with maximum difference of $10.8 \%$ and average difference of $7 \%$.
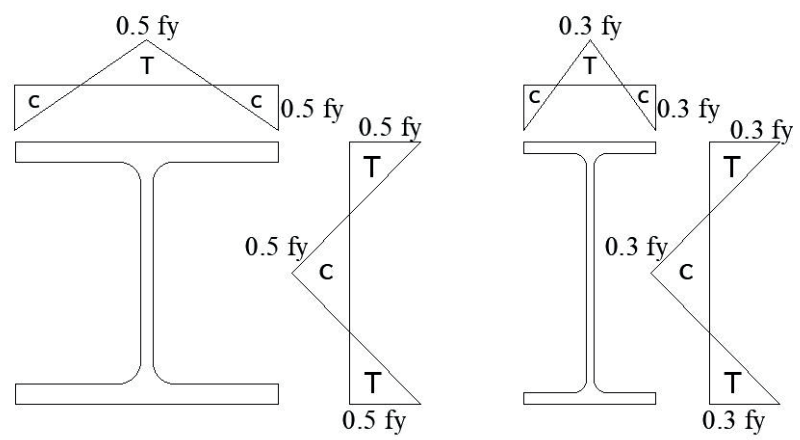

Fig. 4 Considered residual stress patterns for $\mathrm{h} / \mathrm{b}<1.2$ (Left) and $\mathrm{h} / \mathrm{b}>1.2$ (right) [16]
Moreover, The ABAQUS model underestimates the ultimate load of steel columns at elevated temperatures for all cases, and thus it provides a safe side prediction for the fire resistance of steel columns.

Fig. 5 shows the buckling load-axial deflection curves derived from the numerical model of the S19 member which is compared to its respective test response.

These good predictions from the model indicate that the model is capable of predicting buckling capacity of steel columns at elevated temperatures and thus can be used for parametric study presented in this study.

\subsection{Material model}

The S235 steel grade was considered in this study.

The temperature introduced to the numerical model is considered to be uniformly distributed along the member. Thus, the comparison between numerical results and the simple calculation procedure presented in EN 1993-1-2 could be possible. Moreover, it was found in [17] that adopting the constant temperature assumption along the member and cross-section gives the most conservative case (the worst scenario) for assessing the buckling capacity.

Table 2 Comparison of FE and experimental results from Pauli et al. [8].

\begin{tabular}{|c|c|c|c|c|c|c|}
\hline \multirow[t]{2}{*}{ Column ID } & \multirow[t]{2}{*}{$\begin{array}{c}\text { Temp. } \\
{ }^{\circ} \mathrm{C}\end{array}$} & \multicolumn{2}{|c|}{$\begin{array}{c}\text { End } \\
\text { conditions }\end{array}$} & \multirow{2}{*}{$\begin{array}{c}N_{u, t e s t} \\
(\mathrm{kN})\end{array}$} & \multirow{2}{*}{$\begin{array}{c}N_{u, F E A} \\
(\mathrm{kN})\end{array}$} & \multirow{2}{*}{$\frac{N_{u, t e s t}-N_{u, F E A}}{N_{u, t e s t}}$} \\
\hline & & $\mathrm{y}$ & z & & & \\
\hline S19 & 400 & tie & tie & 996 & 964 & $3.3 \%$ \\
\hline S13 & 550 & tie & tie & 511 & 461 & $10.8 \%$ \\
\hline M02 & 400 & tie & pin & 646 & 615 & $5.1 \%$ \\
\hline M03 & 550 & tie & pin & 405 & 367 & $10.4 \%$ \\
\hline
\end{tabular}

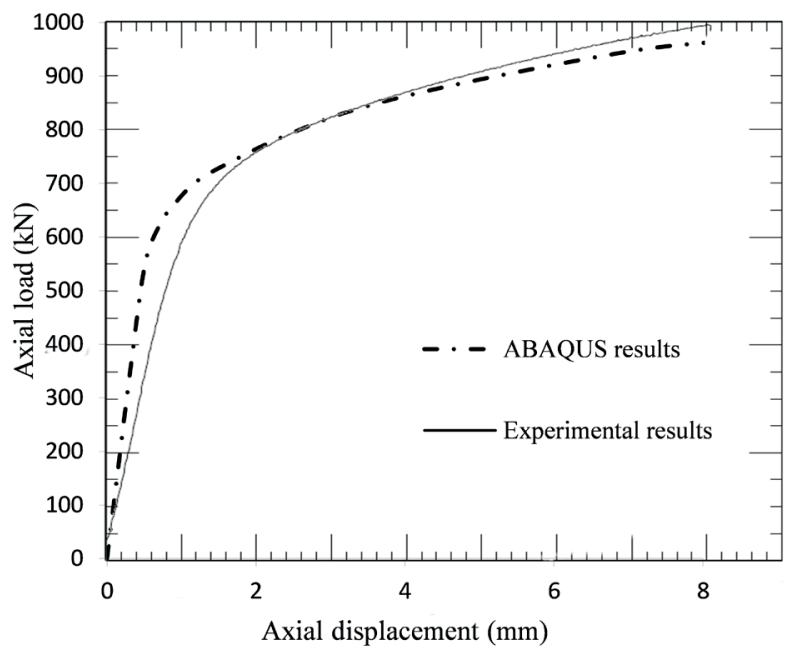

Fig. 5 Comparison of the axial load - displacement curves for S19 column [8] 
Elevated temperatures have big influence on the mechanical properties of the steel material, with key factors being the loss of linearity, and strength.

For linear buckling analysis, linear elastic material law with Young's modulus $E=2.1 \times 10^{5} \mathrm{GPa}$ is used. The Poisson's ratio is set to 0.3 .

For the non-linear analysis at elevated temperature, the reduction factors for the stress-strain relationship of carbon steel at elevated temperatures presented in Table 3.1 of EN 1993-1-2 [1] were used, as shown in Table 3.

The shape of the stress-strain curves at different temperatures as used for the material model is shown in Fig. 6. The influence of thermal expansion has not been considered.

To investigate the effect of mechanical properties on the overall buckling resistance of the studied columns, Bilinear stress-strain diagram with strain-hardening is adopted in the finite element models: linear elastic with $E_{\theta}$ up to $f_{y, \theta}$, then plastic (with a strain hardening slope of $0.01 E_{\theta}$ ), as shown in Fig. 7.

In the finite element models, true stress and plastic strain were adopted instead of engineering stress and strain. Therefore, the following equations were used to represent the relationship between true stress and plastic strain:

$\sigma_{\text {true }}=\sigma_{\text {nom }}\left(1+\varepsilon_{\text {nom }}\right)$,

$\varepsilon_{\text {true }}=\ln \left(1+\varepsilon_{\text {nom }}\right)$,

$\varepsilon_{p l}=\ln \left(1+\varepsilon_{\text {nom }}\right)-\frac{\varepsilon_{\text {true }}}{E}$,

where $\sigma_{\text {true: }}$ : true stress

$\sigma_{\text {nom }}$ : engineering or nominal stress

$\varepsilon_{\text {nom }}$ : engineering or nominal strain

$\varepsilon_{\text {true }}:$ true strain; $\varepsilon_{p l}$ plastic strain

\section{Results}

3.1 Safety of EN1993-1-2 buckling curve with different slenderness values

The load-carrying capacities of columns with different nondimensional slenderness $\left(\bar{\lambda}_{z}\right)$ values were calculated.

Table 3 Reduction factors at steel temperature $\theta$ relative to the value of

$$
f_{y} \text { and } E_{a} \text { at } 20[1]
$$

\begin{tabular}{lccc}
\hline Steel temperature & $k_{y, \theta}$ & $k_{p, \theta}$ & $k_{E, \theta}$ \\
\hline 400 & 1.000 & 0.420 & 0.700 \\
$500 \square$ & 0.780 & 0.360 & 0.600 \\
$600 \square$ & 0.470 & 0.180 & 0.310 \\
\hline
\end{tabular}

The following results can be drawn:

When the non-dimensional slenderness value of the column was:

for IPE180: $\bar{\lambda}_{z}<0.4:\left(\bar{\lambda}_{400^{\circ} \mathrm{C}}=0.478 ; \bar{\lambda}_{500^{\circ} \mathrm{C}}=0.456\right.$; $\bar{\lambda}_{600^{\circ} \mathrm{C}}=0.493$ ),

for HE240A: $\bar{\lambda}_{z}<0.44:\left(\bar{\lambda}_{400^{\circ} \mathrm{C}}=0.538 ; \bar{\lambda}_{500^{\circ} \mathrm{C}}=0.513\right.$; $\left.\bar{\lambda}_{600^{\circ} \mathrm{C}}=0.554\right)$,

local buckling occurred at mid-height of the column.

On the other hand, for higher values of non-dimensional slenderness ratio, the failure mode of the steel columns was the global buckling mode.

The global and local failure deformed shapes are shown in Fig. 8, and Fig. 9, respectively, with U1: is the horizontal displacement of the steel column in millimeters.

The results presented in Figs. 10-13 indicate similar behavior of the columns made of the same cross-section type.

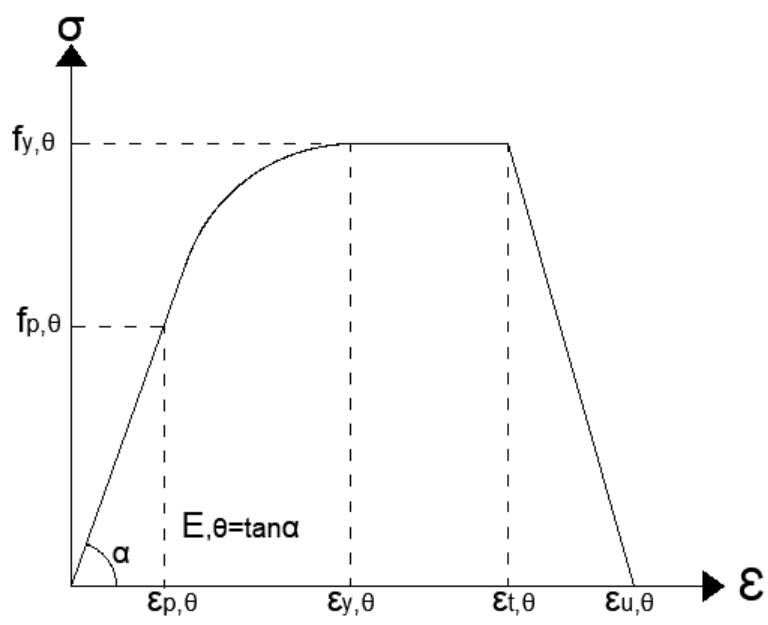

Fig. 6 EN1993-1-2 material model [1]

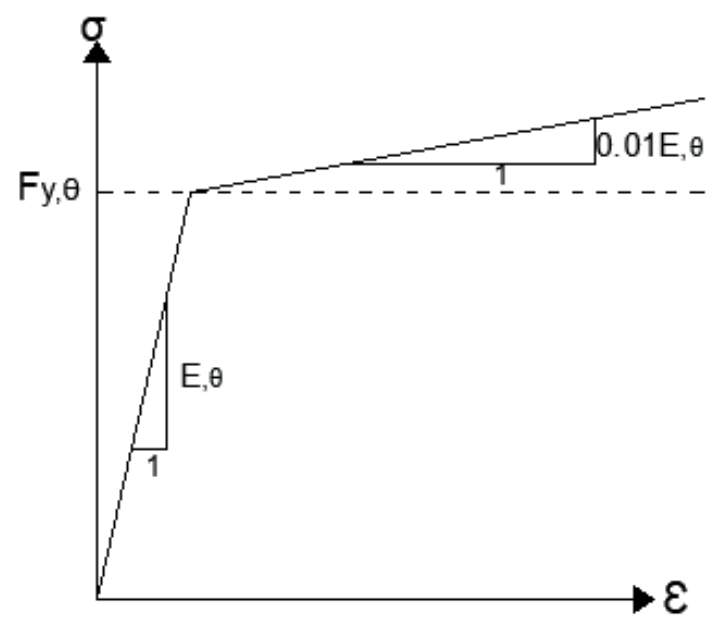

Fig. 7 Bilinear model with hardening 


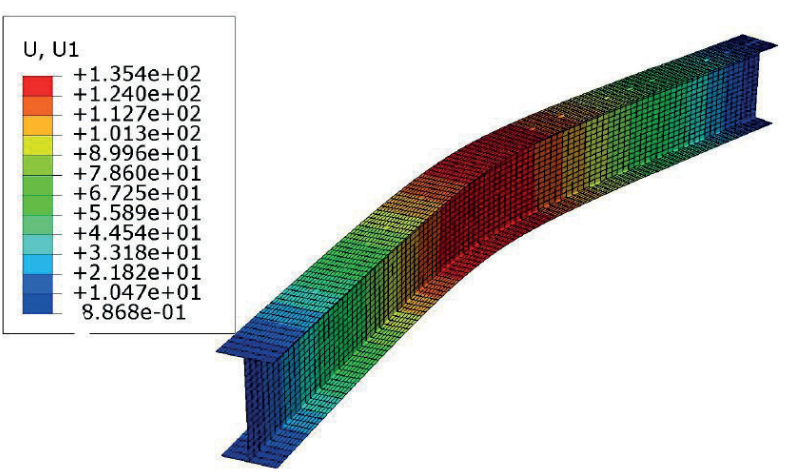

Fig. 8 Global failure mode of columns

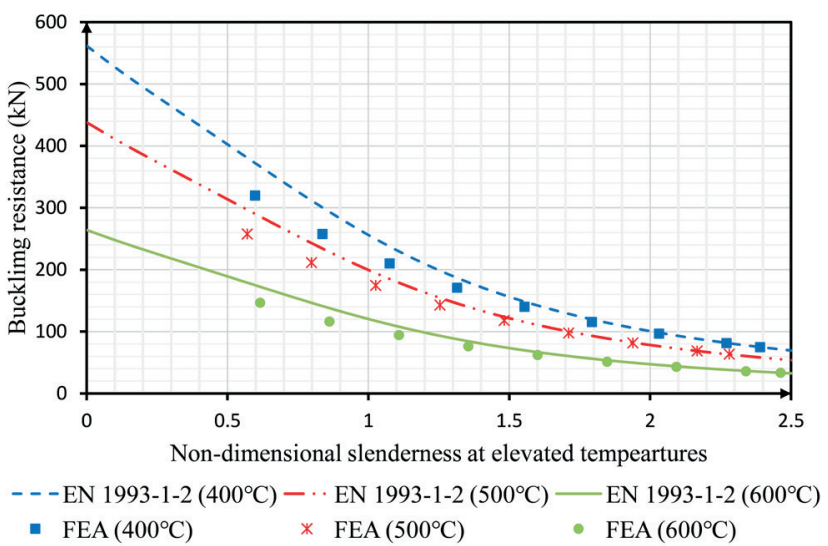

Fig. 10 Comparison of EN 1993-1-2 buckling curves and FE results for IPE180 cross section

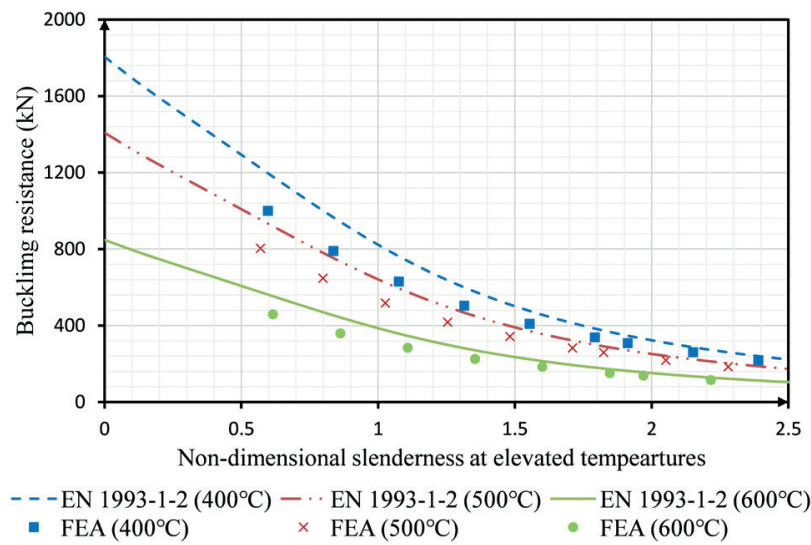

Fig. 12 Comparison of EN 1993-1-2 buckling curves and FE results for HE240A cross-section

Moreover, it can be noted that the EN 1993-1-2 buckling curve overestimates the buckling reduction factors in all cases of columns with non-dimensional slenderness at elevated temperatures less than 1.5 , while the difference between EN 1993-1-2 buckling curve and numerical results becomes smaller for higher non-dimensional slenderness values.

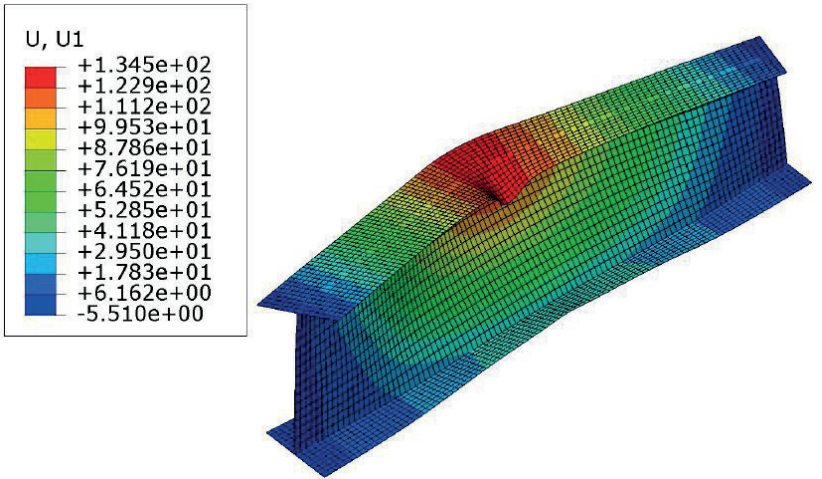

Fig. 9 Local failure mode of columns

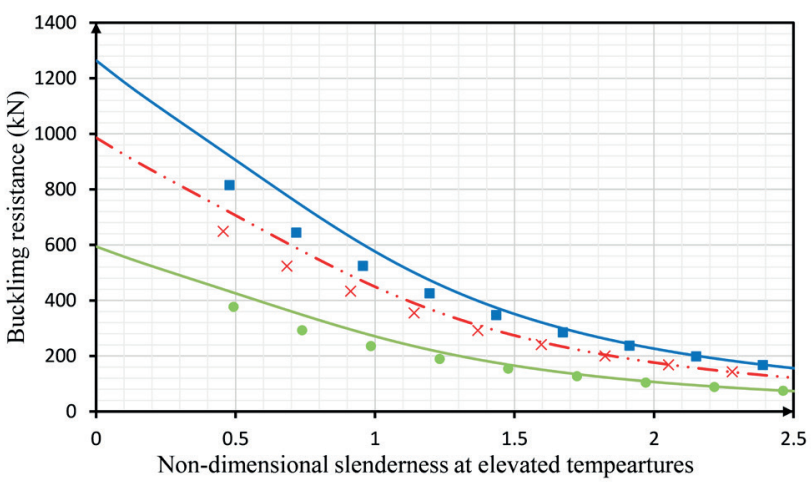

- EN 1993-1-2 $\left(400^{\circ} \mathrm{C}\right)-\cdot \cdot \operatorname{EN~} 1993-1-2\left(500^{\circ} \mathrm{C}\right)-\mathrm{EN} 1993-1-2\left(600^{\circ} \mathrm{C}\right)$

- $\operatorname{FEA}\left(400^{\circ} \mathrm{C}\right) \times \operatorname{FEA}\left(500^{\circ} \mathrm{C}\right) \times \operatorname{FEA}\left(600^{\circ} \mathrm{C}\right)$

Fig. 11 Comparison of EN 1993-1-2 buckling curves and FE results for IPE300 cross section

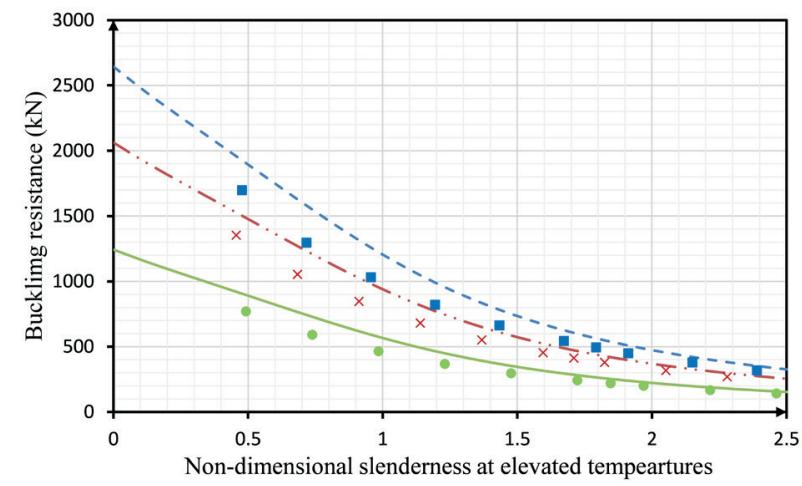

- - -EN 1993-1-2 $\left(400^{\circ} \mathrm{C}\right)-\cdot \cdot \operatorname{EN} 1993-1-2\left(500^{\circ} \mathrm{C}\right)-\mathrm{EN} 1993-1-2\left(600^{\circ} \mathrm{C}\right)$ - $\operatorname{FEA}\left(400^{\circ} \mathrm{C}\right)$ $\times \quad \mathrm{FEA}\left(500^{\circ} \mathrm{C}\right)$ - $\mathrm{FEA}\left(600^{\circ} \mathrm{C}\right)$

Fig. 13 Comparison of EN 1993-1-2 buckling curves and FE results for HE300A cross-section

It can also be seen that the simplified method presented in EN 1993-1-2 for calculating the buckling capacities of steel columns at elevated temperature completely ignores the shape and dimensions of the cross-section, which seems to be not convenient. 


\subsection{Influence of the residual stress}

To illustrate the influence of the residual stress, the finite element analyses of columns with and without residual stress were established. The overall buckling resistances of IPE180, IPE300, HE240A, and HE300A at elevated temperatures are presented in Figs. 14-17, respectively. Moreover, the influence of residual stress on different cross-sections at 500 $\square$ is shown in Fig. 18

It can be seen that the residual stress has different influence on the buckling resistance of steel hot-rolled section columns when the section and steel temperature vary, as follows:

- The influence of residual stress is larger on the columns with HEA cross-sections (maximum of a $19 \%$ reduction of the buckling resistance due to the residual stress) than those with IPE cross-sections (maximum of a $10 \%$ reduction of the buckling resistance due to the residual stress).

- The effect of residual stress is slightly bigger on the columns under $500^{\circ} \mathrm{C}$ than those under $400^{\circ} \mathrm{C}$ or $600^{\circ} \mathrm{C}$.

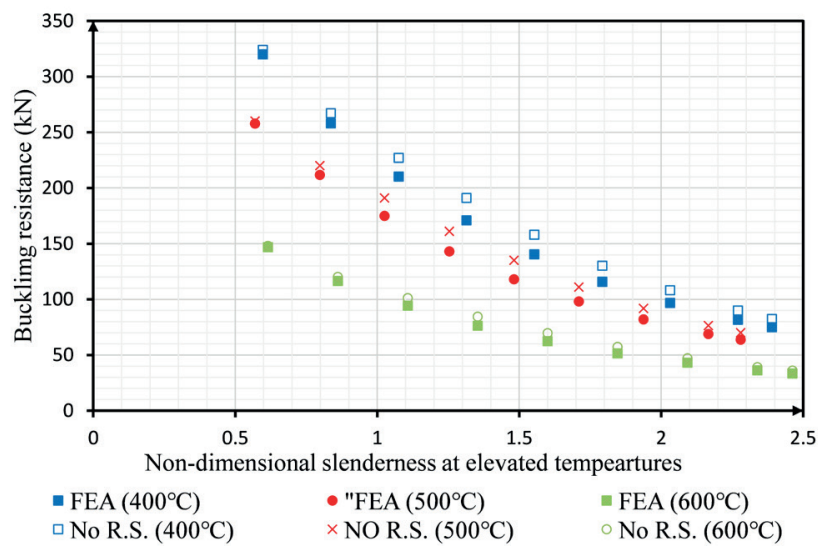

Fig. 14 Influence of residual stress on buckling resistance of columns with IPE180 cross section

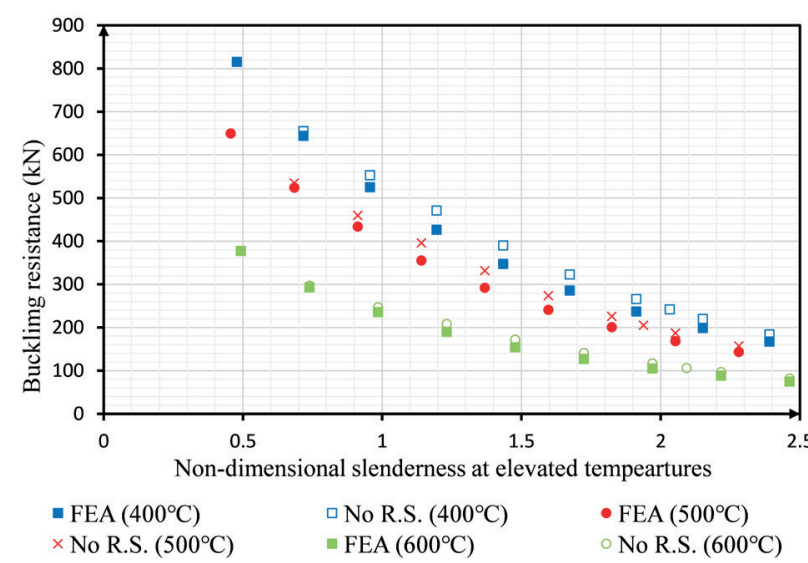

Fig. 15 Influence of residual stress on buckling resistance of columns with IPE300 cross section
- The residual stress has the greatest influence on the overall buckling resistance when the non-dimensional slenderness at elevated temperatures value equals to $\bar{\lambda}_{600 \square}=1.6$ for IPE180 cross-section, $\bar{\lambda}_{600 \square}=$ 1.47 for IPE300, $\bar{\lambda}_{600 \square}=$ for HE240A, and $\bar{\lambda}_{600 \square}=$ for HE300A, as shown in Fig. 19. In general, the influence of residual stress on buckling capacity is the

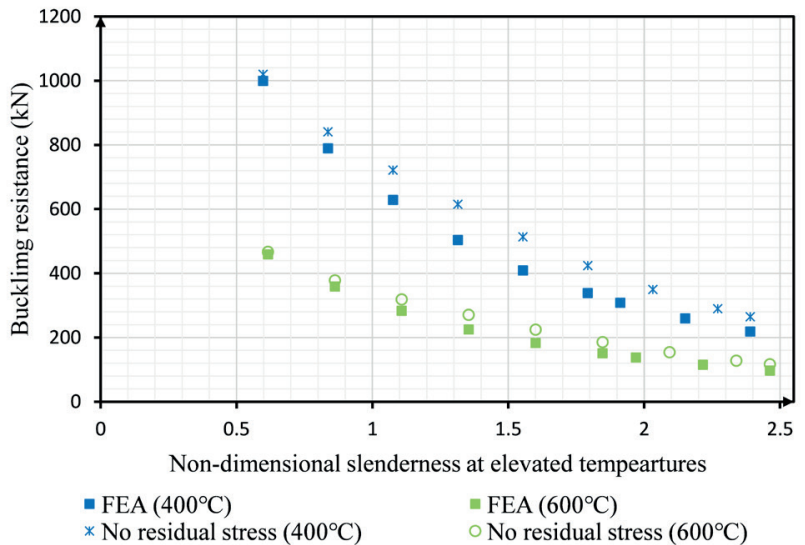

Fig. 16 Influence of residual stress on buckling resistance of columns with HE240A cross section

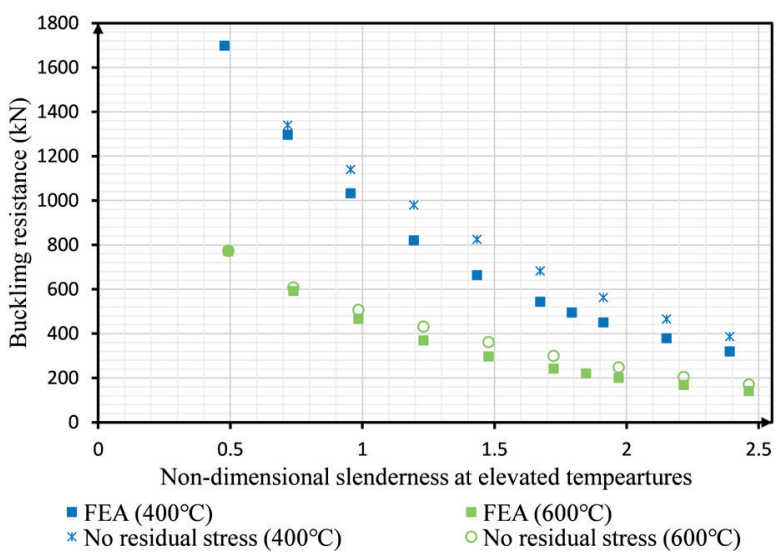

Fig. 17 Influence of residual stress on buckling resistance of column with HE300A cross section

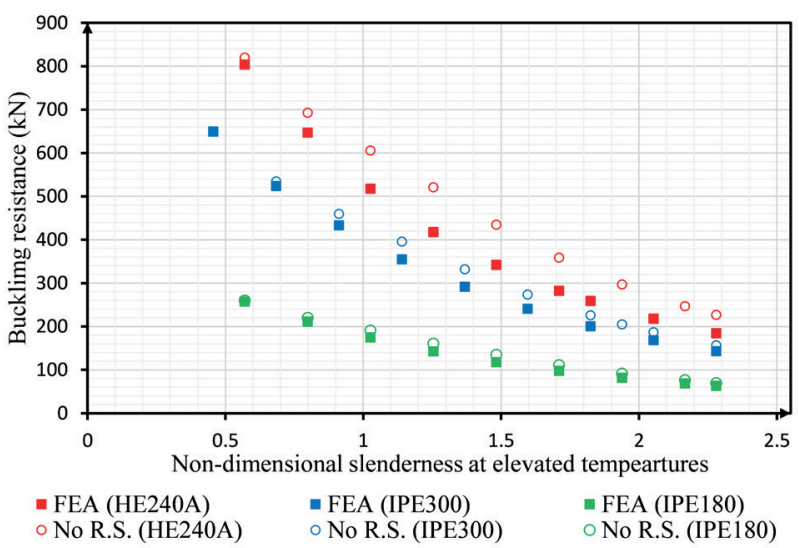

Fig. 18 Influence of residual stress on buckling resistance of columns with different cross sections at 500 


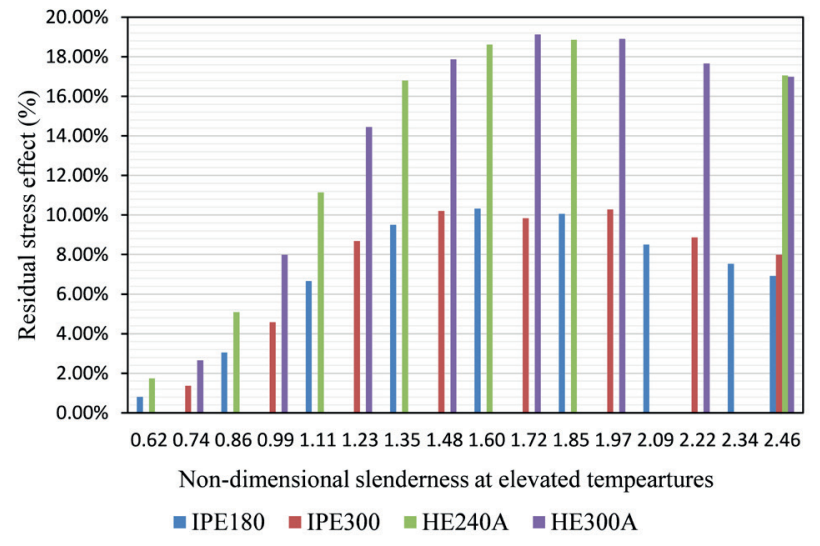

Fig. 19 Influence of residual stress on buckling resistance of columns with different cross-sections at $600 \square$

biggest for intermediate non-dimensional slenderness ratio $\left(\bar{\lambda}_{z}\right)$ between 1.2 and 1.6 , while it becomes smaller for other slenderness ratio.

- The effect of residual stress on the columns with slenderness ratio $\bar{\lambda}_{z, \theta} \leq 0.65$ is negligible.

\subsection{Influence of the mechanical properties of steel}

To investigate the influence of mechanical properties on the overall buckling resistance of steel hot-rolled I-section axial compressed columns at elevated temperatures, two stress-strain constitutive relations including EN 1993-1-2 and Bilinear model are adopted in the finite element models (see Fig. 6 and Fig. 7). The overall buckling resistances of steel columns of IPE300 and HE300A cross-sections calculated by using these two stress-strain relationships are presented in Fig. 20, and Fig. 21, respectively. While Fig. 22 illustrates the influence of mechanical properties on buckling resistance of columns with cross-sections of IPE180, and HE240A at 500 $\square$.

In general, high material nonlinearity leads to reduction of young modulus of steel, and development of the plasticity early results in an increase of deformation and, consequently, reduction of buckling capacity.

The EN 1993-1-2 stress-strain curve for structural steel at elevated temperature adopted in the numerical model has a relatively low proportionality limit (See Table 3), and that leads to much lower buckling loads compared to those calculated using the bilinear material model in which the proportional limit is assumed to be the yield stress.

The yield plateau and material nonlinearity have a significant influence on the buckling capacity of hot-rolled I-section steel columns, and especially for columns with low slenderness ratio (short columns).

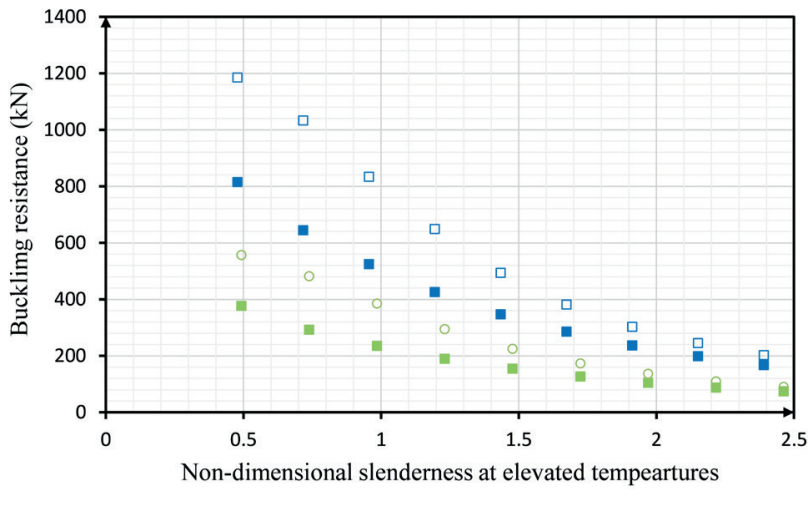

- $\operatorname{FEA}\left(400^{\circ} \mathrm{C}\right) \square \operatorname{Bilinear}\left(400^{\circ} \mathrm{C}\right) \backsim \operatorname{FEA}\left(600^{\circ} \mathrm{C}\right) \circ$ Bilinear $\left(600^{\circ} \mathrm{C}\right)$

Fig. 20 Influence of mechanical properties of steel on buckling resistance of column with of IPE300 cross section

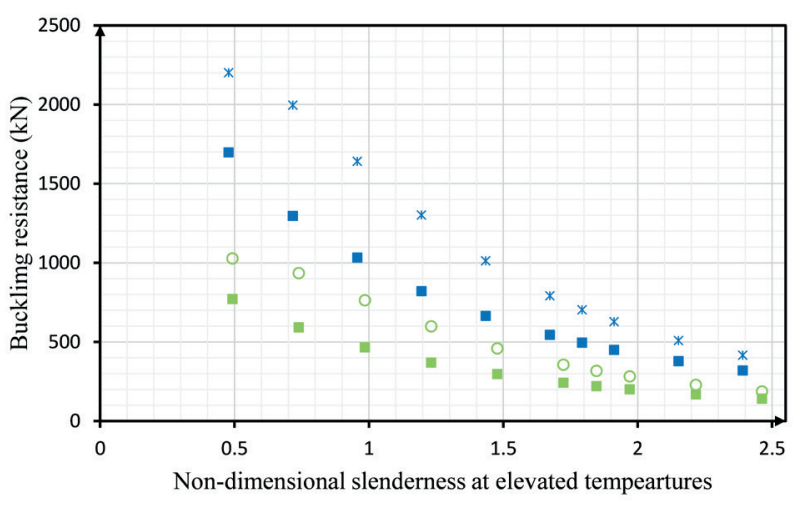

- $\operatorname{FEA}\left(400^{\circ} \mathrm{C}\right)=\operatorname{FEA}\left(600^{\circ} \mathrm{C}\right) *$ Bilinear $\left(400^{\circ} \mathrm{C}\right) \circ$ Bilinear $\left(600^{\circ} \mathrm{C}\right)$

Fig. 21 Influence of mechanical properties of steel on buckling resistance of column with of HE300A cross section

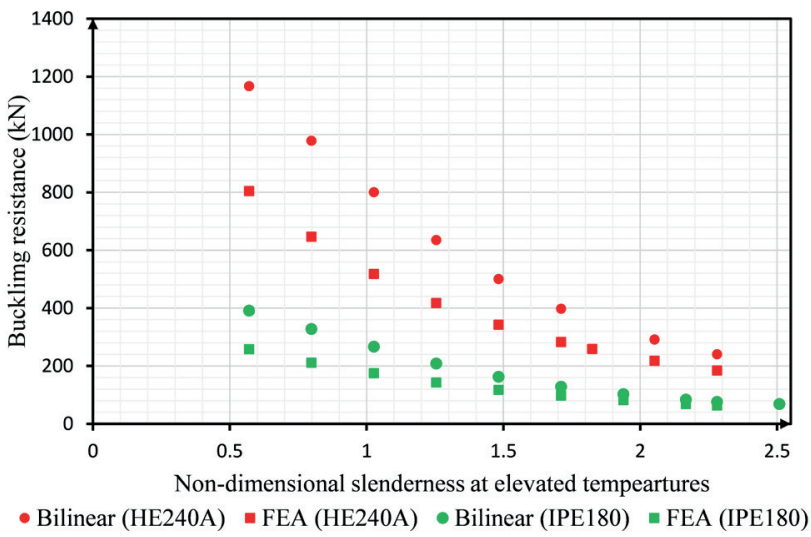

Fig. 22 Influence of mechanical properties of steel on buckling resistance of column with different cross sections at 500

\section{Conclusions}

The buckling behavior of steel columns with IPE and HEA cross-section at elevated temperatures has been investigated. A finite element model was developed and validated using experimental results, then a parametric study was 
carried out. The cross-section dimensions, slenderness ratio, temperature, residual stress, and mechanical properties all have influences on the global buckling resistance.

The results obtained with the finite element model showed that the EN 1993-1-2 simplified method generally leads to unconservative predictions of the buckling capacity of steel columns at elevated temperatures depending on the slenderness ratio, and the cross-section dimensions.

The EN 1993-2 bucking curve significantly overestimates the buckling capacity in the non-dimensional slenderness ratio range of $\bar{\lambda}_{\theta} \leq 1.5$, while the difference between the EN 1993-1-2 buckling curve and the FEM results becomes relatively smaller for higher non-dimensional slenderness values. Moreover, for columns made of HEA cross-sections, the EN 1993-1-2 provisions lead to considerably unsafe results. This can be caused due to the fact that the EN 1993-1-2 simplified method uses only one buckling curve for all sections to determine the buckling resistance at elevated temperatures and makes no distinction between different sections types and different residual stress distributions and magnitudes, which is seen to be not suitable compared to the results of the numerical

\section{References}

[1] CEN "EN1993-1-2: Design of Steel Structures, Part 1 2: General Rules, Structural Fire Design", European Committee for Standardization, Brussels, Belgium, 2005.

[2] Franssen, J.-M., Schleich, J.-B., Cajot, L.-G. "A simple model for the fire resistance of axially loaded members according to Eurocode 3", Journal of Constructional Steel Research, 35(1), pp. 49-69, 1995. https://doi.org/10.1016/0143-974X(94)00042-D

[3] Franssen, J.-M., Schleich, J.-B., Cajot, L.-G., Azpiazu, W. "A simple model for the fire resistance of axially loaded members-comparison with experimental results", Journal of Constructional Steel Research, 37(3), pp. 175-204, 1996. https://doi.org/10.1016/0143-974X(96)00008-9

[4] Szalai, J., Papp, F. "On the theoretical background of the generalization of Ayrton-Perry type resistance formulas", Journal of Constructional Steel Research, 66(5), pp. 670-679, 2010.

https://doi.org/10.1016/j.jcsr.2009.12.013

[5] Kervalishvili, A., Talvik, I. "Modified procedure for buckling of steel columns at elevated temperatures", Journal of Constructional Steel Research, 127, pp. 108-119, 2016. https://doi.org/10.1016/j.jcsr.2016.07.008

[6] Yang, K.-C., Lee, H.-H., Chan, O. "Experimental study of fire-resistant steel H-columns at elevated temperature", Journal of Constructional Steel Research, 62(6), pp. 544-553, 2006. https://doi.org/10.1016/j.jcsr.2005.09.008

[7] Wang, W., Kodur, V., Yang, X., Li, G. "Experimental study on local buckling of axially compressed steel stub columns at elevated temperatures", Thin-Walled Structures, 82, pp. 33-45, 2014. https://doi.org/10.1016/j.tws.2014.03.015 modelling. In general, it can be stated that the EN 1993-1-2 buckling curve is not satisfactory in its current format for steel columns and needs to be recalibrated in order to obtain higher buckling capacities.

Moreover, the results showed that the residual stress has an important impact in the buckling capacity of steel columns at elevated temperatures. The effect of residual stress is larger on the columns with HEA cross-sections with maximum of a $19 \%$ reduction of the buckling resistance due to the residual stress, while the maximum reduction of the buckling resistance due to the residual stress for IPE cross-sections is about $10 \%$.

In addition to that, the influence of the residual stresses in the buckling capacity of columns is bigger for intermediate slenderness ratio $\bar{\lambda}_{z}=1.2-1.6$, while it becomes smaller for other slenderness ratio, and negligible for short columns $\left(\bar{\lambda}_{z, \theta} \leq 0.65\right)$.

To this end, the influences of different factors on the load capacity of steel columns at elevated temperatures are examined with the aim of better understanding the behavior of steel columns and developing the simplified methods presented in EN 1993-1-2.

[8] Pauli, J., Somaini, D., Knobloch, M., Fontana, M. "Experiments on steel columns under fire conditions", Swiss Federal Institute of Technology Zurich, Institute of Structural Engineering, Zurich, Switzerland, Rep. 340, 2012. https://doi.org/10.3929/ethz-a-007600651

[9] Pauli, J. "The Behaviour of Steel Columns in Fire: Material Cross sectional Capacity Column Buckling", Swiss Federal Institute of Technology Zurich, Institute of Structural Engineering, Zurich, Switzerland, Rep. 343, 2012. https://doi.org/10.3929/ethz-a-009754421

[10] Gomes, F. C. T., e Costa, P. M. P., Rodrigues, J. P. C., Neves, I. C. "Buckling length of a steel column for fire design", Engineering Structures, 29(10), pp. 2497-2502, 2007. https://doi.org/10.1016/j.engstruct.2006.11.015

[11] Kervalishvili, A., Talvik, I. "Alternative approach to buckling of square hollow section steel columns in fire", Journal of Constructional Steel Research, 96, pp. 140-150, 2014. https://doi.org/10.1016/j.jcsr.2013.11.018

[12] Knobloch, M., Somaini, D., Pauli, J., Fontana, M. "Stability of steel columns subjected to fire", In: SDSS'Rio 2010 Stability and Ductility of Steel Structures, Rio de Janeiro, Brazil, Sept. 8-10, 2010.

[13] Chen, Y., Wentao, X., Shaohua, H., Kai, W. "Investigation on Mechanical Behavior of I-Section Steel Columns After Elevated Temperature", Fire Technology, 54, pp. 503-529, 2018. https://doi.org/10.1007/s10694-017-0694-7 
[14] BSI "BS EN 1090 2. Execution of steel structures and aluminum structures Part 2: Technical requirements for steel structures", British Standards Institute, London, UK, 2008.

[15] European Convention for Constructional Steelwork. Committee 8, Stability "Manual on stability of steel structures (2nd ed)", European Convention for Constructional Steelwork- ECCS, Brussels, Belgium 1976. [online] Available at: https://www.steelconstruct.com/
[16] Franssen, J.-M. "Residual stresses in steel profiles submitted to the fire: an analogy", In: Proceedings of the 3rd CIB/W14 FSF Workshop on Modelling, Rijswijk, Netherlands, 1993, pp. 103-112. [online] Available at: http://hdl.handle.net/2268/34499

[17] Maia, E., Couto, C., Vila Real, P., Lopes, N. "Influence of non-uniform temperature distributions on the behaviour of I-shaped beams subjected to elevated temperatures", In: Congress on Numerical Methods in Engineering- CMN 2019, Guimarães, Portugal, 2019, pp. $580-598$. 